\title{
Doença de Chagas - primeiro caso autóctone na Amazônia Ocidental - Amazonas - Brasil.
}

\author{
Menabarreto Segadilha França ("); João Macias Frade ("); Kenia Konasugawa ("*); Flávio B de Almeida ("\#")
}

\section{Resumo}

Os autores relatam o primeiro caso autóctone de Doença de Chagas na Amazônia Ocidental, na localidade de Boa Esperança, Município de São Paulo de Olivença, diagnosticado em u'a menor de 4 anos de idade, que nunca saiu do referido municipio. O exame que os levou ao achado fora feito para pesquisa de Plasmodium no mês de outubro de 1979, onde foram evidenciadas inúmeras formas flageladas semelhantes ao T. cruzi. Foram feitos dois Xenodiagnósticos com ninfas de $4 .^{\circ}$ e $5 .^{\circ}$ estágios de $\mathbf{R}$. prolixus, obtendo-se confirmação da infecção pelo T. cruzi .

\section{INTRODUÇÃo}

A Doença de Chagas, no Brasil, alastra-se por todo o território nacional (Corrêa, 1976). Segundo Rodrigues \& Mello (1942), a exceção seria a Região Amazônica, compreendendo os Estados do Amazonas, Acre, Pará e os Territórios Federais do Amapá, Roraima e Rondônia.

A partir de 1968, são descritos os primeiros casos autóctones de Doença de Chagas na Região Amazônica, na parte oriental e em particular, no Estado do Pará (Shaw et al. 1969).

No Território do Amapá, o primeiro caso autóctone de Doença de Chagas é relatado por Júnior et al. (1974).

Frahia Neto (1977) refere através do estudo do "Panorama Atual das Parasitoses na Amazônia", o total de sete casos autóctones de Doença de Chagas, no Estado do Pará.

Silveira et al. (1980) relatam o oitavo caso autóctone de Doença de Chagas na Amazônia Oriental, Estado do Pará.
Na Amazônia Ocidental e em particular no Estado do Amazonas, é confirmada a existência de triatomíneos e de $T$. cruzi (Almeida, 1971; Almeida \& Machado, 1971).

No que diz respeito à Tripanosomíase na Amazônia Ocidental, os primeiros estudos datam de 1910 feitos por Cruz et al., Osvaldo Cruz (1971), quando da sua viagem empreendida ao rio Juruá, achado que os referidos pesquisadores não conseguiram elucidar.

Em 1971, por ocasião do VII Congresso da Sociedade Brasileira de Medicina Tropical, em Manaus, Amazonas (Martins) foi referido o encontro de Triatomíneos em duas residências localizadas num conjunto habitacional recém-consruído nos arredores de Manaus.

Ferraroni et al. (1977) relatam seis casos humanos suspeitos, apresentando positividade aos exames sorológicos na área do Município de Barcelos, às margens do rio Negro, Estado do Amazonas. Desses seis (6) casos suspeitos, quatro (4) foram examinados por Almeida \& Nunes de Mello (1978) e apresentaram negatividade aos exames de gota espessa, inoculação de sangue em rato e comundongo, xenodiagnóstico e hemocultura.

Estando executando um trabalho de tese Mansonelose, próximo à área em questão, fomos solicitados pelo microscopista da SUCAM, Cláudio Coelho, para dar parecer diagnóstico sobre o exame de uma lâmina preparada para pesquisa de Plasmodium. em que verificamos a presença de formas flageladas semelhantes ao $T$. cruzi. (Fig. 1).

\footnotetext{
(*) $\rightarrow$ Universidade do Amazonas e Instituto de Medicina Tropical de Manaus - AM.

(*) - Instituto de Medicina Tropical de Manaus - AM.

(“.”) - Instituto Nacional de Pesquisas da Amazônia, Manaus.
} 


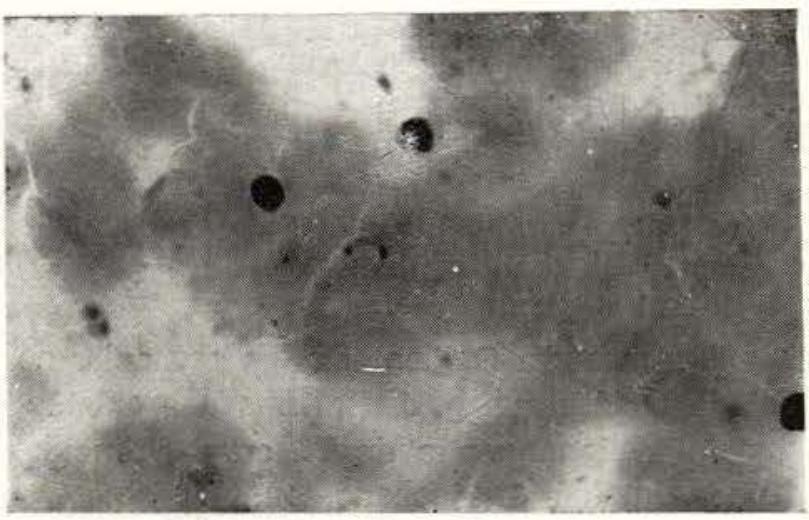

Fig. 1 - Formas flageladas semelhantes ao T. cruzi.

\section{MATERIAL E MÉTODOS}

DESCRIÇÃ́O DE CASO

Trata-se de uma criança (S.N.S.) com 4 anos de idade, sexo feminino, parda, amazonense, residente em Boa Esperança, no Município de São Paulo de Olivença, que apresentava "febre e inchação no corpo" (sic). No dia $20 / 09 / 80$, a paciente apresentou febre alta de natureza contínua com ligeiras remissões, edema generalizado e modificações da coloração da pele. Um mês após, a paciente voltou a apresentar os mesmos sintomas acima referidos.

Obs.: Segundo informações do microscopista da SUCAM, lotado em Benjamin Constant, para onde as lâminas são enviadas para pesquisa de Plasmodium, todas foram negativas.

A criança mora em casa com paredes e piso de paxiúba, com teto de palha e zinco, com três (3) cômodos, sem luz elétrica, sem instalações sanitárias e com o abastecimento de água feito no rio. Nunca se ausentou do Amazonas e em particular do Município de São Paulo de Olivença. Reside com os pais e quatro (4) irmãos, sendo que o pai é natural do Estado do Ceará, de onde veio para o Amazonas, ainda criança.

Os exames Clínico, Radiológico e Eletrocardiográfico realizados por nós seis (6) meses após o início da doença, foram considerados normais.

\section{Resultados}

\section{EXAMES COMPLEMENTARES}

Foram realizados dois (2) Xenodiagnósticos com dez (10) ninfas de $R$. prolixus. As ninfas utilizadas no primeiro Xenodiagnóstico, foram examinadas um mês após, sendo que, das dez (10) ninfas empregadas, somente oito (8) tiveram repasto satisfatório, tendo sido encontradas nas fezes de um barbeiro, forma de Tripomastigota de $T$. cruzi. (Fig. 2).

Camundongos inoculados com fezes e conteúdo intestinal do barbeiro positivo do primeiro Xenodiagnóstico, apresentaram formas flageladas, a partir do $6^{\circ}$ dia de inoculação. (Fig. 3).

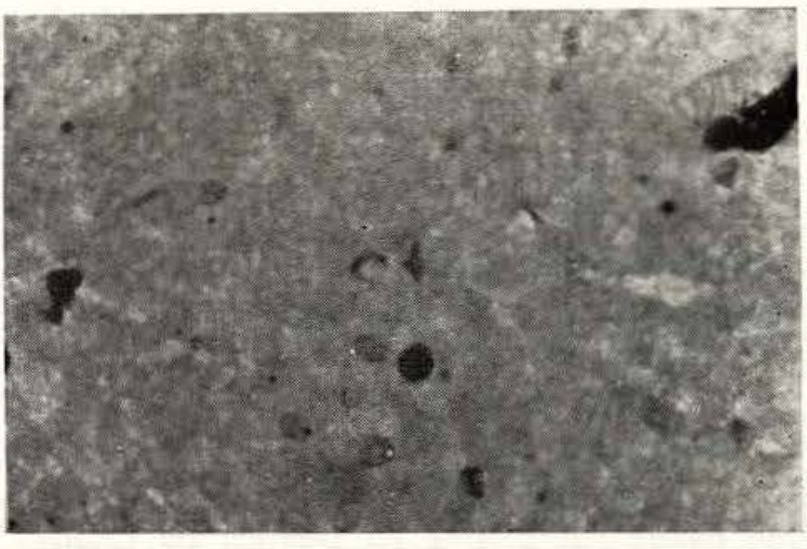

Fig. 2 - Fezes de um barbeiro onde foi encontrada forma de Tripomastigota de T. cruzi

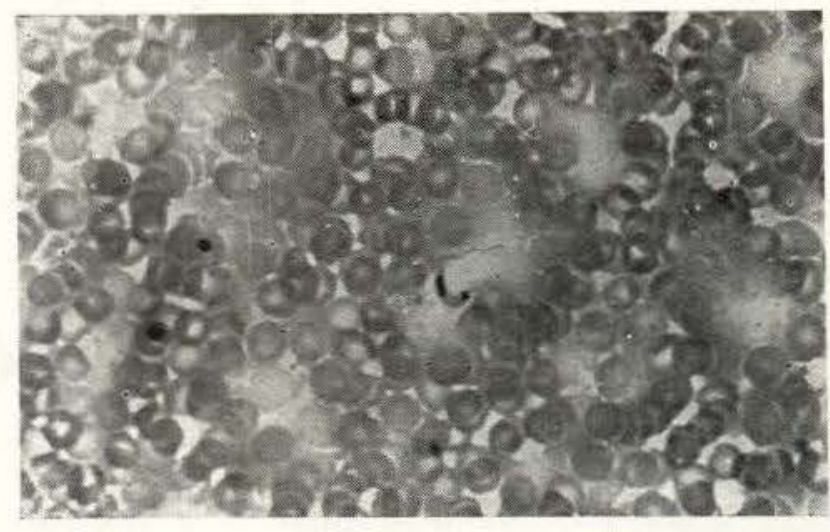

Fig. 3 - Conteúdo intestinal do barbeiro positivo do primeiro xenodiagnóstico inoculado em camundongo, apresentando formas flageladas a partir do $60^{\circ}$ dia de inoculação. 
Ao exame histopatológico dos camundongos positivos que foram inoculados com fezes e conteúdo intestinal do barbeiro do primeiro Xenodiagnóstico, observamos :

Um quadro de miocardite caracterizado por infiltrado inflamatório ora focal, ora difuso, no endomísio ao longo das fibras musculares com predomínio de linfócitos, acompanhados de plasmócitos, histiócitos e granulócitos neutrófilos; não sendo, entretanto, evidenciado amastigota ou ninhos de amastigotas nas fibras cardíacas.

O segundo Xenodiagnóstico lido a partir do trigésimo dia após a sua feitura, apresentou resultado negativo.

Quanto à sorologia realizada pelo Dr. Mário Camargo em São Paulo, foram obtidos títulos de $1 / 40$ para Hemaglutinação, bem como $1 / 40$ para Imunofluorescência, às custas de 1gG.

\section{COMENTÁRIOS E CONCLUSÕES}

Não resta a menor dúvida de que estamos diante de um caso autóctone de Doença de Chagas. O que nos preocupa é a possibilidade da domiciliação do barbeiro, visto que. sabemos de sua existência na região, cujo habitat é predominantemente silvestre. A população de Boa Esperança já está familiarizada com o mesmo, visto que já existem denominações específicas como Camareta, dado seu odor característico, e Jurupari por causa de sua coexistência com o demônio.

Conseguimos capturar dois (2) exemplares de triatomíneos: um (1) $R$. pictipes e um (1) $R$. robustus dentro do mosquiteiro de uma casa próxima à da paciente. Os dois (2) exemplares apresentaram-se infectados com $T$. cruzi, que, inoculados em camundengos apresentaram positividade a partir do $6^{\circ}$ dia. (Fig. 4).

O que podemos concluir, com base nos dados de nossas observações, é a necessidade de uma investigação mais ampla no Amazonas, a fim de que possamos conhecer a
Extensão do problema Doença de Chagas, riesta região.

Fizemos um estudo epidemiológico na área em questão, cujos dados serão publicados oportunamente.

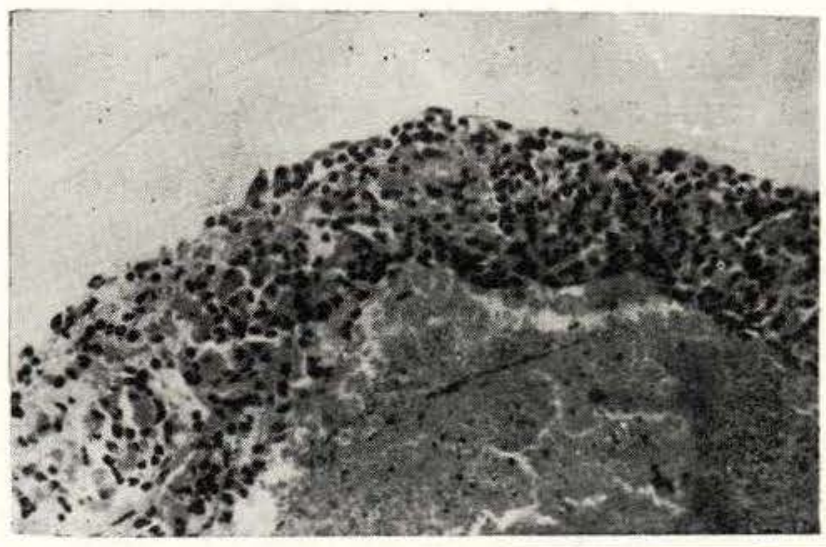

Fig. 4 - Inoculação em camundongo, de material fecal de triatomídeos infectados com T. cruzi, apresentando positividade a partir do $60^{\circ}$ dia.

\section{AgRAdECIMENTOS}

Os autores agradecem ao Diretor Geral do Instituto de Medicina Tropical de Manaus, bem como ao Diretor da SUCAM, pelo integral apoio dispensado, ao Professor J. Rodrigues Coura pelas correções do texto, ao Professor Mário Camargo pela execução dos exames sorológicos, à pesquisadora do INPA, Dra. Mok, pelo fornecimento dos camundongos utilizados em nossa pesquisa, e ao Técnico em Entomologia Nelson F. Fé, pela captura dos barbeiros e dos reservatórios silvestres.

\section{SUMMARY}

The authors report the first known authochthonous case of Chagas disease in Western Amazonia. The patient, a four year old girl from the village of Boa Es. perança in São Paulo de Olivença county, had never lived in nor visited any other locality.

In october of 1979, in the course of their study of Plasmodium in that area, the lab technicians of SUCAM came across a slide presenting numerous flagellated forms which were subsequently identified by the authors as T. cruzi.

The $T$. cruzi infection was confirmed by two xenodiagnoses using 4 th and 5 th stage $\mathbf{R}$. prolixus Nymphs 


\section{BIBLIOGRAFIA}

ALMEIDA, F.B.

1971 - Triatomíneos da Amazônia - Encontro de três espécies naturalmente infectadas por Trypancsoma semelhante ao cruzi, no Estado do Amazonas, (Hemiptera, Reduvidae). Acta Amazonica, 1 (11): 89-93.

ALmeida, F.B. \& Machado, P.A.

1971 - Sobre a infecção natural do Panstrogyllus genicullatus pelo Tripanosoma cruzi em Manaus, Amazonas, Brasil, apresentado no VII Congresso da Sociedade Brasileira de Medicina Tropical, Manaus, AM. Acta Amazo. nica, 1 (2): 71-75.

Almeida, F.B. \& Nunes de Mello, J.A.

1978 - Sobre a ocorrência de moléstia de Chagas no Estado do Amazonas, Brasil. Acta Ama. zonica, 8 (4): 595-599

CORRÊA, R.R.

1976 - Informe sobre a Doença de Chagas no Brasil e em especial, no Estado de São Paulo (Relatório Oficial do Tema III, Doença de Chagas. In: 16 Congresso Brasileiro de $\mathrm{Hi}$ giene realizado em Curitiba.

Ferraroni, J.J.; Nunes de Mello, J.A. \& CAMARgo, M.E. 1977 - Moléstia de Chagas na Amazônia. Occrrência de seis (6) casos suspeitos, autóctones sorologicamente positivos. Acta Ama. zonica, 7 (3): 438-440.

FRAHI NeTO, $\mathrm{H}$.

1977 - Panorama atual das parasitoses na Amazônia. Belém - SUDAM - p. 36 ilust.
JÚNIOR, R.G.; FARIA, J.I.; MATE, J.R.; COSTA, R.; Salgado, A.; Mourão, D.; Santos, C.P.C. \& Nohmi, M. 1974 - Doença de Chagas - Registro do primeiro diagnóstico feito no homem, no Território Federal do Amapá. In: Congresso da Sociedade Brasileira de Medicina Tropical, Curitiba-Paraná.

MARTINS, L.M.

1971 - Estudos e Investigaçōes sobre a Problemática da Doença de Chagas na Amazônia Ocidental. In: 7 Congresso da Sociedade Brasileira de Medicina Tropical, Manaus., (mimeografado).

Oswaldo Cruz; Carlos Chagas; Afrânio peixoto

1971 - Sobre o saneamento da Amazônia. Compilação por Djalma Batista. Manaus, p. 68-69.

RODRIGUES, B.A. \& MELO, G.B.

1942 - Contribuiçăo ao Estudo da Tripanosomíase Americana. Mem. Instituto Oswaldo Cruz, 37: $41-90$

Shaw, J.; Lainson, R. \& Frahia, H.

$196 y$ - Considerações sobre a epidemiologia dos primeiros casos autóctones da Doença de Chagas, em Belém, Pará, Brasil. Rev. Saúde Pública, 3 (2): 153-157.

Silveira, F.T.; Dias, M.G.V.; Pardal, P.P.; Lobão, A.D. \& MELO, G.B.

1980 - Oitavo caso autóctone de Doença de Chagas registrado no Pará, Brasil. Hiléia Médica, Belém, 1 (1): 1-10.

(Aceito para publicação em 19/11/80) 